\title{
Recognition memory and awareness: Occurrence of perceptual effects in remembering or in knowing depends on conscious resources at encoding, but not at retrieval
}

\author{
JOHN M. GARDINER \\ University of Sussex, Brighton, England \\ VERNON H. GREGG \\ University of London, London, England \\ and \\ IRENE KARAYIANNI \\ University of Sussex, Brighton, England
}

\begin{abstract}
We report four experiments in which a remember-know paradigm was combined with a response deadline procedure in order to assess memory awareness in fast, as compared with slow, recognition judgments. In the experiments, we also investigated the perceptual effects of study-test congruence, either for picture size or for speaker's voice, following either full or divided attention at study. These perceptual effects occurred in remembering with full attention and in knowing with divided attention, but they were uninfluenced by recognition speed, indicating that their occurrence in remembering or knowing depends more on conscious resources at encoding than on those at retrieval. The results have implications for theoretical accounts of remembering and knowing that assume that remembering is more consciously controlled and effortful, whereas knowing is more automatic and faster.
\end{abstract}

It has been widely believed that consciousness of memory is unitary, in the sense that one is either conscious or not conscious of memory. It has also been widely believed that consciousness may be intractable to science, because of its intrinsic subjectivity. Both these beliefs were challenged by new concepts of consciousness introduced by Tulving $(1983,1985)$. Tulving proposed that there are two mind-brain systems, episodic and semantic memory, and that one of their chief distinguishing characteristics is that they give rise to two different kinds of consciousness: autonoetic and noetic, respectively. These two kinds of consciousness are, in turn, expressed in two kinds of subjective experiences, which he termed remembering and knowing. Remembering entails traveling back in time mentally to think again about some previous personal event and what was experienced at the time of its original occurrence. It is intimately bound up with a sense of oneself as a person with a continuing historical identity and a future into which one can also travel mentally (see Tulving, 2002, 2005). Knowing does not entail any such experience but involves a more abstract awareness of the

This research was supported by Grant 000220015 from the ESRC, and we are grateful for their support. Correspondence should be addressed to J. M. Gardiner, Psychology Department, School of Life Sciences, University of Sussex, Brighton BN1 9QH, England (e-mail: j.m.gardiner@ sussex.ac.uk). past, not only of general knowledge that one has acquired, but also of personal events for which memory is experienced only in a factual way, without any awareness of mentally reliving those events. Tulving $(1983,1985)$ also demonstrated that people could distinguish between remembering and knowing even in standard list-learning experiments and report which of those two kinds of experiences occurred at the time they retrieved individual list items. Since then, a considerable amount of evidence has accumulated indicating that reports of remembering and knowing, despite their subjectivity, are perfectly amenable to scientific inquiry. Such reports have yielded a large, systematic, and theoretically intelligible set of replicable findings (see Gardiner \& Richardson-Klavehn, 2000, for a review). Gardiner and Richardson-Klavehn (see also Gardiner \& Conway, 1999) characterized these findings as providing evidence of functional independence between remembering and knowing. Different independent variables have been found to selectively affect reports of one or the other of the two states of awareness, to have opposite effects on them, or to have similar effects on them. Remembering and knowing have also been dissociated by different subject variables, which have included various clinical populations, and by various measures of brain function.

By far, the majority of these findings have come from recognition memory experiments in which people typically have had to judge which test items had previously occurred 
in a studied list. And in most of these experiments, reports of remembering and knowing have been given following a yes response in a yes/no recognition judgment. In Tulving's $(1983,1985)$ theory, recognition accompanied by remembering reflects retrieval from the episodic system, whereas recognition accompanied by knowing reflects retrieval from the semantic system. Moreover, in his SPI model of process relations between these two systems, encoding into semantic and episodic memory is serial, storage is parallel, and retrieval is independent (Tulving, 1995). Thus, the occurrence of events is first registered in semantic memory before it can be encoded into episodic memory, and both systems may contribute independently to the subsequent recognition of those events.

Because much of the evidence comes from the use of a remember-know paradigm in recognition memory experiments, it has also been widely interpreted by other theories more specifically geared toward recognition memory. The most prominent of these theories have been dual-process models of recognition that distinguish between two independent processes of recollection and familiarity (Jacoby, 1991; see, also, Mandler, 1980). In these models, the recollection process gives rise to experiences of remembering, and the familiarity process gives rise to experiences of knowing; hence, the two states of awareness reflect the two processes that are assumed to determine recognition. In a remember-know paradigm, however, remember and know responses are exclusive (although, for an exception, see Higham \& Vokey, 2004). This means that know responses underestimate the independent contribution of the familiarity process. This has led to the proposal of an independence remember-know model, in which the familiarity process is estimated by a correction based on the proportions of remember responses (Yonelinas \& Jacoby, 1995). Process estimates derived from this model and those derived from other procedures, particularly from the process-dissociation procedure (Jacoby, 1991) and from receiver-operating characteristics (ROCs), have been extensively compared by Yonelinas (2002) and shown to be in quite good agreement (see, also, Rugg, Schloerscheidt, \& Mark, 1998).

In contrast with the memory systems approach, for which the reported states of awareness are usually taken to be the primary data, for dual-process models it is the process estimates that can be derived from those reports that are of primary interest. Hence, whether or not one chooses to use the independence remember-know model depends partly on one's theoretical orientation. In many cases, though, its use leads to different conclusions only by showing that there are effects in estimates of the familiarity process in the absence of any such effects in know responses (see Yonelinas, 2002; for more discussion, see Jacoby, Yonelinas, \& Jennings, 1997; Richardson-Klavehn, Gardiner, \& Java, 1996). Operationally, the important point to appreciate is that in the systems approach, know responses indicate retrieval from semantic memory in the absence of episodic memory and that in dual-process models, know responses indicate familiarity in the absence of recollection.
The reported states of awareness are also the primary data for a third account largely developed by Rajaram (1993, 1996, 1999). In her approach, process distinctions are used to predict the effects of various independent variables on the two states of awareness. Initially, it was suggested that conceptual manipulations influenced remembering but not knowing and that perceptual manipulations influenced knowing but not remembering (Rajaram, 1993; see, too, Gardiner, 1988). Evidence that there were some perceptual factors that influenced remembering and some conceptual factors that influenced knowing led to a revised account. In this account, it is distinctiveness of processing that selectively affects remembering and fluency of processing that selectively affects knowing, regardless, in each case, of whether that processing is conceptual or perceptual (see, e.g., Rajaram, 1996; Rajaram \& Geraci, 2000).

One of the perceptual effects that led to this distinctiveness/fluency model was that of study-test congruence in picture recognition memory (Rajaram, 1996). In one of her experiments, pictures showing simple line drawings of familiar everyday objects were shown for study in one of two sizes, small or large, and then, at test, they appeared either in the same size as at study or in the alternate size. Recognition performance was superior with size congruence at study and test, and this size congruence effect occurred in remembering, not in knowing. Yonelinas and Jacoby (1995) had found similar effects of size congruence in recognition memory for randomly generated geometric shapes, and unlike Rajaram (1996) — who did not use the independence remember-know model - they also found an effect of size congruence in familiarity estimates that they derived from remember and know responses. The picture size congruence effect that Rajaram (1996) obtained in remembering was replicated by Gardiner, Gregg, Mashru, and Thaman (2001). And a similar perceptual effect of congruence in remembering was found by Karayianni and Gardiner (2003) for a speaker's voice, when words were presented for study in one of two alternate voices, male or female, and then, at test, were presented either in the same voice as at study or in the alternate voice.

It is these perceptual effects of picture size and speaker's voice with which we were concerned in the present experiments, not only in relation to the three theories that we have outlined, but also in relation to a much broader theoretical issue. This broader issue concerns the impact of the conscious resources available at encoding, and at retrieval, on the occurrence of these effects and the states of awareness with which they are associated. In all three theoretical accounts, it is commonly assumed that remembering depends on consciously controlled processing and that it is strategic and effortful, whereas knowing is more automatic, nonstrategic, and reflexive. This difference was one of the original defining features that distinguished episodic from semantic memory (Tulving, 1983), and it continues to be very influential (see, e.g., Levine, Freedman, Dawson, Black, \& Stuss, 1999). It has also been critical to some dual-process models that distinguish recollection from familiarity, such as the model embodied in Jacoby's 
(1991) process dissociation procedure. And the assumption that distinctive processing involves more attention, whereas fluency of processing arises automatically, seems implicit in the very terms distinctiveness and fluency in Rajaram's (1996) distinctiveness/fluency model.

Two previous sets of studies led directly to interest in this general issue. In one set of studies, conscious resources were reduced at encoding by the addition of a divided attention task (Gardiner et al., 2001; Karayianni $\&$ Gardiner, 2003). In the other set of studies, conscious resources were reduced at retrieval by having a speeded recognition test (Gardiner, Konstantinou, Karayianni, \& Gregg, 2005; Gardiner, Ramponi, \& Richardson-Klavehn, 1999; Konstantinou \& Gardiner, 2005).

It has previously been established that the addition of a divided attention task at study, such as monitoring a series of auditory tones or of digits, greatly reduces remembering but does not reduce knowing (Gardiner \& Parkin, 1990; Parkin, Gardiner, \& Rosser, 1995). More recently, Mangels, Picton, and Craik (2001) replicated this finding in an event-related brain potentials (ERP) study, from which they concluded that whereas some minimal level of analysis at encoding is sufficient to lead to know responses in recognition memory, remember responses depend on much more extensive brain activity - particularly, sustained interaction of frontal and posterior regions. All these findings are in good agreement with Tulving's (1995) SPI model and the assumption that encoding into semantic memory depends on minimal conscious resources, unlike encoding into episodic memory, which demands more attention. These findings are equally compatible with other theoretical accounts, such as the idea that familiarity may be based on fluency, whereas recollection depends on more elaborative, distinctive processing.

These theoretical ideas would be even more strongly supported by evidence that with the addition of a divided attention task at study, effects in memory that normally occur in remembering are, instead, observed in knowing. Gardiner et al. (2001) obtained what we believe is the first evidence of this sort. They showed that with divided attention at study, as compared with full attention, the picture size congruence effect occurred in knowing, not in remembering. Karayianni and Gardiner (2003) found similar results for the voice congruence effect, albeit for nonwords, rather than for words. Thus, similar perceptual effects at the behavioral level occurred either in remembering or in knowing, depending on the conscious resources available at encoding. In the present experiments, we aimed to replicate and extend these findings. But instead of comparing the impact of divided attention with full attention directly, these two study conditions were used in separate experiments, with a view to obtaining perceptual effects in one or the other state of awareness and then manipulating the conscious resources available at retrieval.

As compared with their effects at study, divided attention tasks at test are relatively ineffective (see Anderson, 2001, for a review), and so we manipulated conscious resources at retrieval by comparing fast with slow recognition judgments, using a response deadline procedure.
In this procedure, people are trained to make recognition judgments at different time intervals following the onset of the test items. The general assumption is that more conscious resources can be brought to bear on slow recognition judgments than on those made as fast as possible. Our experiments were predicated on this assumption. This assumption has also been used to test those dual-process models that distinguish a relatively fast, automatic familiarity process from a relatively slow, controlled recollection process. It follows from such models that fast recognition judgments, in comparison with slow ones, should be more dependent on familiarity and less dependent on recollection. And indeed, there is a considerable amount of evidence to support this claim, both at a behavioral level (e.g., Boldini, Russo, \& Avons, 2004; Jacoby, Jones, \& Dolan, 1998; Toth, 1996) and at a physiological level (e.g., Curran, 2000; Curran \& Cleary, 2003).

The question that arises is whether the occurrence of the perceptual effects of picture size and voice congruence in remembering or in knowing depends on the conscious resources available at retrieval, as well as on those available at study. To address this question, in each experiment, we compared recognition judgments made with a very short response deadline and those made with a very long response deadline. With a long deadline, we expected to replicate these perceptual effects either in remembering, following full attention at study, or in knowing, following divided attention at study. With a short deadline, the possible outcomes are more uncertain, and there are a number of alternate hypotheses. The effects may depend on more consciously controlled retrieval, regardless of whether encoding conditions lead to their initial occurrence in remembering or in knowing. If so, the effects may not occur at all with a short response deadline. Alternatively, the effects may not depend much on more consciously controlled retrieval, in which case they should occur at both response deadlines. Moreover, one might hypothesize that at the short deadline, the effects would be observed in knowing, regardless of whether they occurred in knowing or in remembering at the long deadline, because at the short deadline they should be more automatic.

The possible outcomes here are also relevant to Tulving's (1993) coordination hypothesis. The coordination hypothesis concerns the relation between awareness at encoding and awareness at retrieval. The idea is that the retrieval of information from a memory system is possible only at a level of awareness that does not exceed the level of awareness that pertained to the system at the time of encoding. Information cannot be retrieved from a system into which it was not encoded. Thus, if effects occur in knowing as a result of encoding, they should not occur in remembering as a result of retrieval. But the converse does not follow, so evidence of effects in remembering at the long deadline but in knowing at the short deadline would also be consistent with the coordination hypothesis, as would be evidence that effects remain either in remembering or in knowing, regardless of response deadline.

If one general theoretical issue is the impact of the conscious resources available at encoding, or at retrieval, on 
the perceptual effects of picture size and voice congruence, another, related one is the appropriate characterization of the two states of awareness themselves - that is, remembering or knowing - with respect to their conscious demands. It has previously been suggested that, rather than identify remembering with more effortful, controlled processing and knowing with less demanding, automatic processing, there is an orthogonal relationship between these two kinds of distinctions of consciousness (see, e.g., Gardiner et al., 1999; Richardson-Klavehn et al., 1996; Richardson-Klavehn, Gardiner, \& Ramponi, 2002). That is, remembering may sometimes also be less demanding and more automatic, as well as, at other times, being effortful and controlled. And knowing may sometimes also be more effortful and controlled, as well as, at other times, being less demanding and more automatic.

Some of the support for this more orthogonal view of the relation between the two states of awareness and the conscious resources they may require has come from the few previous studies in which the remember-know paradigm has been used with a response deadline procedure. Gardiner et al. (1999) found not only that levels-of-processing effects occurred at short as well as at long deadlines, replicating results obtained by Toth (1996), but also that those effects occurred in remembering at both response deadlines. That the effects occurred at the short deadline suggests, as Toth had concluded, a degree of automaticity. But that automaticity did not lead to effects being observed in know responses. Gardiner et al. (1999) also found that knowing, as well as remembering, increased from the short to the long response deadline, suggesting that both states of awareness benefited from the greater opportunity for conscious control afforded by the longer deadline. Konstantinou and Gardiner (2005) replicated both levels-ofprocessing effects and the increase in knowing from a short to a long deadline in recognition memory for lists of faces of famous people, rather than for lists of words. And in both of these studies, there was no interaction between the levels-of-processing and response deadline.

Those results contrasted with results obtained by Gardiner et al. (2005). They investigated the picture size congruence effect at short and long response deadlines, but although the effect occurred at both deadlines, it was significantly reduced at the shorter one. Moreover, there was no significant increase in knowing from the short to the long deadline. It is unclear why there were these discrepancies in the results of the different studies, and they clearly indicate the need for a more definitive empirical resolution, which the present experiments were intended to provide.

We report four experiments. In the first two, picture size and voice congruence effects, respectively, were investigated at short (under $700 \mathrm{msec}$ ) and long (over $3,000 \mathrm{msec}$ ) response deadlines following full attention at study. In the third and fourth experiments, those same effects were investigated under the same test conditions following divided attention at study. For the long deadlines, the perceptual effects of study-test congruence were predicted to occur in remembering in the first two experiments and in knowing in the last two experiments.
At issue was to what extent, if at all, those perceptual effects would occur at the short deadlines and, if they did, whether it would be in remembering or in knowing. It was also predicted that in all four experiments, knowing, as well as remembering, would increase from the short to the long deadline.

\section{METHOD}

\section{Participants}

One hundred ninety-two participants took part in the experiments. All of them were students from the University of Sussex, who were tested individually and were paid for their participation. There were 48 participants in each of the four experiments, 24 of whom were randomly assigned to a 700-msec deadline condition and 24 of whom were randomly assigned to a 3,000-msec deadline condition. One participant in Experiment 2 and 2 participants in Experiment 3 in the 700 -msec deadline conditions failed to follow test instructions and were replaced.

\section{Design and Materials}

The design for all four experiments was a $2 \times 2$ mixed factorial design, with congruence (same vs. different) as the within-subjects factor and response deadline (700 vs. $3,000 \mathrm{msec}$ ) as the betweensubjects factor. In Experiments 1 and 3, picture size congruence was manipulated, and in Experiments 2 and 4, voice congruence was manipulated.

The experiments used two sets of materials. Experiments 1 and 3 used pictures and Experiments 2 and 4 used spoken words. The 132 pictures were selected from Snodgrass and Vanderwart's (1980) norms, with the restriction that they had a name agreement score of at least $85 \%$ according to the norms. Each of these pictures was created in two versions, a small and a large one. The size ratio between the two versions was 1:2.7. For Experiments 2 and 4, medium- and low-frequency words were spoken by either a male or a female voice. The words were 132 three- or four-syllable medium- and low-frequency English nouns. They were selected from the Medical Research Council (MRC) psycholinguistic database and had a mean frequency count of 5 in Kučera and Francis's (1967) norms. Each of the words was recorded twice, once in a male voice and once in a female voice. These items were digitally recorded at a $44.1 \mathrm{kHz}, 8$-bit sampling rate, using $\mathrm{Cu}-$ base VST sound engineering software. They were normalized for volume and amplitude levels. The items were then recorded on a $C D$ to be played back to the participants on headphones via an Apple Macintosh (iMac) with OS 9, which controlled the presentation and timing.

The items were presented via a computer. Each study list contained 30 large and 30 small pictures (Experiments 1 and 3) or 30 words spoken by a male voice and 30 by a female voice (Experiments 2 and 4), in a random order. At test, the 60 studied items were mixed with 60 lures. Half of the studied and nonstudied items were presented in large size (or by a male voice), and the other half in small size (or by a female voice), so that half of the studied items were presented in the same size or voice at study and test. The items were fully counterbalanced over conditions, which resulted in four study lists and two test lists. The remaining 12 items were used for practice purposes before the actual test. Six were presented in a small size or a male voice, and 6 in a large size or a female voice.

For the pictures and the spoken words, respectively, Experiments 1 and 2 involved full attention at encoding, and Experiments 3 and 4 involved divided attention at encoding. The divided attention tasks were monitoring either a sequence of spoken digits or pairs of visually displayed digits.

\section{Procedure}

The participants were tested individually. For the full-attention size congruence experiment, the participants had to give judgments for the orientation of the pictures during the study phase. They had 
to tick their answers on a piece of paper that had three columns (left, right, and no orientation). For the full-attention voice congruence experiment, the participants had to rate every word in terms of its clarity or pronounceability on a 5-point scale, where 1 was not clear or pronounceable at all and 5 was very clear and pronounceable. Again, they had to tick on a piece of paper that had five columns. These tasks were employed to ensure the participants' attention. The participants were told that they had to attend to the items and do the appropriate study task for each experiment and that they then would do some kind of a memory test. The study lists were presented at a rate of $5 \mathrm{sec}$ per item.

In Experiments 3 and 4, there were divided attention tasks at study. In Experiment 3, this task was to monitor a random sequence of spoken digits and to report every time there were three successive even numbers. In Experiment 4, two random pairs of digits were shown on a computer screen either side of a central point, and the task was to report whether both pairs of digits were odd, both were even, or one pair was odd and the other even.

After study, the participants were engaged in a distractor task for $20 \mathrm{~min}$. This task involved playing backgammon, checkers, or chess with the computer, through the Hoyle Board Games application program. In the test phase, the participants had to make a yes/no recognition decision for every item, and if their answer was yes, give remember, know, or guess responses. The test lists for all the experiments were presented using PsyScope with Mac OS 9.2 on an iBook.

The participants were then given instructions for the recognition test and the deadline procedure, according to which group they belonged to, and were told how to give remember, know and guess judgments. The first 12 items of the test served as practice, so that the participants would be familiarized with the deadline procedure. They were not included in the analysis.

Recognition responses were given on a keyboard that had two buttons labeled yes (old item) and no (new item). If the participants believed that the test item had been encountered in the study list, they had to press yes with their right index finger. If they thought the item was new, they had to press no with their left index finger. If the response was yes, they made the remember/know/guess response orally as soon as they pressed the button (this was done almost simultaneously), and the experimenter recorded these responses. The instructions for the remember/know responses were closely modeled after those used by Rajaram (1996), with some necessary adjustments in the experiments in which spoken words were used. A remember response was defined as occurring when recognition was accompanied by conscious recollection of the item's presence in the study list - that is, becoming consciously aware again of something that had been experienced at the time the item had first been presented. A know response was defined as occurring when recognition was accompanied only by strong feelings that the item had indeed been presented in the study list and not by any conscious recollection of anything that had been specifically experienced at the time of its original presentation. The participants were also told that they had to recognize the test items, regardless of their size or the voice they were heard in. In order to minimize false alarm rates and differences between false alarm rates at each deadline, the participants were strongly discouraged from guessing.

The test items were presented as follows. First, a set of dots appeared in the center of the screen for $1,000 \mathrm{msec}$, to indicate the appearance of the picture or that a word was about to be heard. Then, in Experiments 1 and 3, the picture appeared at the center of the screen. According to the experimental condition, the pictures in the test list remained on the center of the screen for 700 or 3,000 msec (timed from the onset of the test item). For Experiments 2 and 4, there was a blank screen while each word was heard. The mean duration of the words was $959.5 \mathrm{msec}$. In the 700-msec condition, the participants had to give their recognition decision by pressing the appropriate keys before the picture disappeared or before the end of the word. In the 3,000-msec condition, they had to press the appropriate key im- mediately after the offset of the stimulus, in the case of a picture, or after the offset of the blank screen, in the case of a spoken word. The picture (or the blank screen) disappeared as soon as the answer was given or 700/3,000 msec after its onset. Pressing the key triggered the appearance of a set of asterisks, providing the indication to report the state of awareness if the answer was yes. If the answer was no, the experimenter pressed a key to go to the set of dots signaling the next item. The reports of remember/know/guess were given orally as quickly as possible, almost simultaneously with the pressing of yes or no.

\section{RESULTS}

Before describing the results of each experiment, we will note a few points about the way the data were scored and analyzed. We included all of the fast recognition decisions that were made no later than $70 \mathrm{msec}$ after the 700-msec deadline. In so doing, we were able to include virtually all the decisions made in the relevant conditions in these experiments. However, scoring fast recognition decisions in the two experiments in which word lists were spoken presented a novel problem, because of the length of time it takes to perceive spoken words. Studies in which this has been analyzed have shown that a spoken word of this length is typically perceived some $150 \mathrm{msec}$ before the end of the word (see, e.g., Van Petten, Coulson, Rubin, Plante, \& Parks, 1999). Accordingly, we used the latency data to set an actual deadline in which yes decisions made up to $550 \mathrm{msec}$ after the end of the spoken words were included (which, with the 150-msec allowance, equates to a 700-msec deadline, starting from the time at which the word could have been perceived). We then also added the allowance for decisions made up to a further $70 \mathrm{msec}$ after this deadline. In so doing, we were again able to include virtually all the available data. No comparable allowance for the duration of spoken words was made for the 3,000msec deadline.

The results of Experiment 1 are summarized in Table 1. The first row of the table shows the mean proportions of yes responses in the recognition tests. The remaining rows show those proportions partitioned into the states of awareness reported for them. For the main statistical analyses, we describe the results of separate ANOVAs for recognize, remember, and know responses to studied items and the results of separate $t$ tests for overall false alarm rates to unstudied items. We do not report any statistical analyses for guess responses, since these responses were uniformly low and similar for all the conditions and items in all four experiments. For the same reasons, we do not report statistical analyses for false alarm rates partitioned into remember and know responses. An alpha level of .05 was used for all tests.

The mean proportions in Table 1 indicate that there were effects of both response deadline and size congruence and that the effect of size congruence occurred with fast as with slow recognition judgments. Both these effects apparently occurred in remember responses. Although there was little or no indication of any effect of size congruence in know responses, these responses tended to show an effect of response deadline similar to 
Table 1

Mean Proportions of Responses and Standard Deviations for Fast and Slow Recognition as a Function of Size Congruence and Following Full Attention at Study

\begin{tabular}{|c|c|c|c|c|c|c|c|c|c|c|c|c|}
\hline \multirow{3}{*}{$\begin{array}{l}\text { Response } \\
\text { Category }\end{array}$} & \multicolumn{4}{|c|}{ Congruent } & \multicolumn{4}{|c|}{ Incongruent } & \multicolumn{4}{|c|}{ Unstudied } \\
\hline & \multicolumn{2}{|c|}{ Fast } & \multicolumn{2}{|c|}{ Slow } & \multicolumn{2}{|c|}{ Fast } & \multicolumn{2}{|c|}{ Slow } & \multicolumn{2}{|c|}{ Fast } & \multicolumn{2}{|c|}{ Slow } \\
\hline & $M$ & $S D$ & $M$ & $\overline{S D}$ & $M$ & $S D$ & $M$ & $S D$ & $M$ & $S D$ & $M$ & $S D$ \\
\hline ecognize & .66 & .17 & .80 & .1 & .58 & .1 & .71 & .16 & .16 & .08 & .11 & .09 \\
\hline Remember & .37 & .11 & .48 & .14 & .31 & .14 & .38 & .15 & .04 & .03 & .02 & .03 \\
\hline Know & .23 & .11 & .28 & .16 & .22 & .09 & .29 & .15 & .06 & .05 & .06 & .06 \\
\hline Guess & .06 & .05 & .04 & .04 & .05 & .05 & .05 & .04 & .06 & .04 & .03 & .03 \\
\hline
\end{tabular}

that shown by remember responses. For recognition, the main effects of both deadline $\left[F(1,46)=13.02, M S_{\mathrm{e}}=\right.$ $0.03]$ and size congruence $\left[F(1,46)=15.49, M S_{\mathrm{e}}=0.03\right]$ were significant, and there was no interaction between them $(F<1)$. For remember responses, the main effects of deadline $\left[F(1,46)=5.99, M S_{\mathrm{e}}=0.03\right]$ and size congruence $\left[F(1,46)=45.72, M S_{\mathrm{e}}=0.03\right]$ were significant and so too was the interaction between them $[F(1,46)=$ $4.98, M S_{\mathrm{e}}=0.03$ ], reflecting the somewhat smaller effect of size congruence at the short deadline. For know responses, there was no significant effect of size congruence $(F<1)$, a marginally significant effect of deadline $\left[F(1,46)=2.92, M S_{\mathrm{e}}=0.03, p<.10\right]$, and no interaction $(F<1)$. The tendency for a higher overall false alarm rate at the shorter deadline was also marginally significant $[t(46)=1.88, p<.07]$.

The results of Experiment 2 are summarized in Table 2, from which it seems that the pattern of results was, in general, similar to that in Experiment 1. The mean proportions in Table 2 indicate that there were effects in recognition of both response deadline and voice congruence and that the effect of voice congruence occurred with fast as with slow recognition judgments. Both of these effects apparently occurred in remember responses. Although there was little or no indication of any effect of voice congruence in know responses, these responses tended to show a similar effect of response deadline to that shown by remember responses. For recognition, the main effects of both deadline $[F(1,46)=$ $\left.49.98, M S_{\mathrm{e}}=0.03\right]$ and voice congruence $[F(1,46)=35.21$, $\left.M S_{\mathrm{e}}=0.03\right]$ were significant, and there was no interaction between them $(F<1)$. For remember responses, the main effects of deadline $\left[F(1,46)=28.82, M S_{\mathrm{e}}=0.02\right]$ and of voice congruence $\left[F(1,46)=130.85, M S_{\mathrm{e}}=0.02\right]$ were significant, and the interaction between them was marginally significant $\left[F(1,46)=3.03, M S_{\mathrm{e}}=0.02\right]$, since the effect of voice congruence tended to be smaller at the short deadline. For know responses, there was no significant effect of voice congruence $(F=1.43)$, but the effect of deadline was significant $\left[F(1,46)=25.60, M S_{\mathrm{e}}=\right.$ $0.01]$, and there was no interaction $(F=2.38)$. The overall false alarm rate was significantly greater with slow than with fast recognition judgments $[t(46)=2.93]$.

The results of Experiment 3 are summarized in Table 3, from which it seems that the pattern of results was, in general, rather different from that in Experiments 1 and 2. The mean proportions in Table 3 indicate that there were effects of both response deadline and size congruence and that the effect of size congruence occurred with fast as with slow recognition judgments. But neither of these effects apparently occurred in remember responses. And it was the know responses that showed effects of both response deadline and size congruence. For recognition, the main effects both of deadline $\left[F(1,46)=15.41, M S_{\mathrm{e}}=\right.$ $0.03]$ and size congruence $\left[F(1,46)=23.90, M S_{\mathrm{e}}=0.03\right]$ were significant, and there was no interaction between them $(F<1)$. For remember responses, neither the main effect of deadline nor that of size congruence was significant, nor was there any interaction ( $F<1$ in each case). For know responses, there was a significant effect of both response deadline $\left[F(1,46)=18.31, M S_{\mathrm{e}}=0.01\right]$ and size congruence $\left[F(1,46)=45.53, M S_{\mathrm{e}}=0.01\right]$ and no interaction $(F<1)$. The overall false alarm rates did not differ significantly $(t<1)$.

The results of Experiment 4 are summarized in Table 4. The mean proportions in Table 4 indicate that there were effects of both response deadline and voice congruence and that the effect of voice congruence occurred with fast as with slow recognition judgments. Only the effect of response deadline apparently occurred in remember responses. Know responses showed effects of both response

Table 2

Mean Proportions of Responses and Standard Deviations for Fast and Slow Recognition as a Function of Voice Congruence and Following Full Attention at Study

\begin{tabular}{|c|c|c|c|c|c|c|c|c|c|c|c|c|}
\hline \multirow{3}{*}{$\begin{array}{l}\text { Response } \\
\text { Category }\end{array}$} & \multicolumn{4}{|c|}{ Congruent } & \multicolumn{4}{|c|}{ Incongruent } & \multicolumn{4}{|c|}{ Unstudied } \\
\hline & \multicolumn{2}{|c|}{ Fast } & \multicolumn{2}{|c|}{ Slow } & \multicolumn{2}{|c|}{ Fast } & \multicolumn{2}{|c|}{ Slow } & \multicolumn{2}{|c|}{ Fast } & \multicolumn{2}{|c|}{ Slow } \\
\hline & $M$ & $S D$ & $M$ & $S D$ & $M$ & $S D$ & $M$ & $S D$ & $M$ & $S D$ & $M$ & $S D$ \\
\hline Recognize & .48 & .14 & .73 & .13 & .36 & .14 & .61 & .16 & .11 & .05 & .16 & .06 \\
\hline Remember & .29 & .12 & .45 & .10 & .16 & .11 & .28 & .10 & .03 & .03 & .04 & .03 \\
\hline Know & .16 & .06 & .24 & .10 & .15 & .07 & .28 & .12 & .05 & .04 & .07 & .04 \\
\hline Guess & .03 & .03 & .04 & .05 & .04 & .04 & .05 & .05 & .03 & .03 & .06 & .04 \\
\hline
\end{tabular}


Table 3

Mean Proportions of Responses and Standard Deviations for Fast and Slow Recognition as a Function of Size Congruence and Following Divided Attention at Study

\begin{tabular}{|c|c|c|c|c|c|c|c|c|c|c|c|c|}
\hline \multirow{3}{*}{$\begin{array}{l}\text { Response } \\
\text { Category }\end{array}$} & \multicolumn{4}{|c|}{ Congruent } & \multicolumn{4}{|c|}{ Incongruent } & \multicolumn{4}{|c|}{ Unstudied } \\
\hline & \multicolumn{2}{|c|}{ Fast } & \multicolumn{2}{|c|}{ Slow } & \multicolumn{2}{|c|}{ Fast } & \multicolumn{2}{|c|}{ Slow } & \multicolumn{2}{|c|}{ Fast } & \multicolumn{2}{|c|}{ Slow } \\
\hline & $M$ & $S D$ & $M$ & $S D$ & $M$ & $S D$ & $M$ & $S D$ & $M$ & $S D$ & $M$ & $S D$ \\
\hline Recognize & .54 & .12 & .69 & .11 & .49 & .14 & .63 & .14 & .15 & .09 & .13 & .07 \\
\hline Remember & .30 & .13 & .32 & .09 & .30 & .15 & .31 & .12 & .05 & .05 & .03 & .04 \\
\hline Know & .22 & .09 & .32 & .09 & .15 & .08 & .26 & .09 & .05 & .05 & .06 & .05 \\
\hline Guess & .02 & .03 & .05 & .06 & .03 & .03 & .07 & .05 & .05 & .06 & .04 & .04 \\
\hline
\end{tabular}

deadline and voice congruence. For recognition, the main effects of both deadline $\left[F(1,46)=42.78, M S_{\mathrm{e}}=0.03\right]$ and voice congruence $\left[F(1,46)=20.32, M S_{\mathrm{e}}=0.03\right]$ were significant, and there was no interaction between them $(F<1)$. For remember responses, the main effect of deadline was significant $\left[F(1,46)=37.36, M S_{\mathrm{e}}=\right.$ $0.01]$, but the effect of voice congruence was not, nor was the interaction $(F<1$ in each case). For know responses, there was a significant effect of both response deadline $\left[F(1,46)=14.96, M S_{\mathrm{e}}=0.02\right]$ and voice congruence $\left[F(1,46)=44.79, M S_{\mathrm{e}}=0.02\right]$ and no interaction $(F<1)$. The overall false alarm rate was significantly greater with slow than with fast recognition judgments $[t(46)=3.09]$.

It seems useful at this point to summarize the main points emerging from these results, before describing the results of some ancillary analyses. There are several clear trends in the pattern of results across all four experiments. First, the perceptual effects of size and voice congruence occurred in remembering with full attention at encoding and in knowing with divided attention at encoding, replicating previous findings reported by Gardiner et al. (2001) and Karayianni and Gardiner (2003). Second, these perceptual effects occurred with fast, as well as with slow, recognition judgments, suggesting that, in contrast with encoding, they were not much influenced by the conscious resources available at retrieval. Third, the effects remained in remembering, as well as in knowing, regardless of response deadline, in keeping with Tulving's (1993) coordination hypothesis and contrary to the hypothesis that, at the short deadline, the effects would be observed in knowing, regardless of whether they occurred in knowing or in remembering at the long deadline, because at the short deadline they should be more automatic. Fourth, there was a general tendency, although more marked in some experi- ments than in others, for knowing, as well as remembering, to increase with slower, more effortful recognition.

There was also some indication of an interaction between these perceptual effects and the effects of response deadline when they occurred in remembering, but not when they occurred in knowing. The perceptual effects tended to be smaller in remembering at the short response deadline than at the long response deadline. Although this effect was statistically significant in only one of the two cases, it was also obtained by Gardiner et al. (2005), and so it should not be dismissed lightly. The implication is that there may be some small impact of the conscious resources available at retrieval when the effects occur in remembering, but not when they occur in knowing. Set against this, however, is the fact that in no case was this interaction observed in overall correct recognition, and so it could conceivably reflect some small trade-off between the reported states of awareness.

The absence of any effect of response deadline on remembering, in Experiment 3, is puzzling, and we have no ready explanation for this. It is the only occasion, in any of the experiments we have done using this procedure, in which we have observed such an outcome, so we are inclined to dismiss it, especially since, in all other essential respects, the results of this experiment were as expected.

\section{Ancillary Analyses}

In this section, we describe some results from ancillary analyses of the data - that is, analyses in which the data were measures derived from the reported states of awareness. One set of ancillary analyses entailed corrections to those reports in which the corresponding false alarm rates were taken into account. We did this in two ways. In one analysis, we used a high-threshold correction (hit rates minus false alarm rates). In the other analysis, we used a

Table 4

Mean Proportions of Responses and Standard Deviations for Fast and Slow Recognition as a Function of Voice Congruence and Following Divided Attention at Study

\begin{tabular}{|c|c|c|c|c|c|c|c|c|c|c|c|c|}
\hline \multirow{3}{*}{$\begin{array}{l}\text { Response } \\
\text { Category }\end{array}$} & \multicolumn{4}{|c|}{ Congruent } & \multicolumn{4}{|c|}{ Incongruent } & \multicolumn{4}{|c|}{ Unstudied } \\
\hline & \multicolumn{2}{|c|}{ Fast } & \multicolumn{2}{|c|}{ Slow } & \multicolumn{2}{|c|}{ Fast } & \multicolumn{2}{|c|}{ Slow } & \multicolumn{2}{|c|}{ Fast } & \multicolumn{2}{|c|}{ Slow } \\
\hline & $M$ & $S D$ & $M$ & $S D$ & $M$ & $S D$ & $M$ & $S D$ & $M$ & $S D$ & $M$ & $S D$ \\
\hline Recognize & .46 & .10 & .69 & .17 & .36 & .12 & .62 & .17 & .13 & .04 & .17 & .05 \\
\hline Remember & .13 & .06 & .24 & .09 & .13 & .06 & .24 & .10 & .03 & .02 & .03 & .03 \\
\hline Know & .31 & .08 & .41 & .11 & .21 & .10 & .31 & .11 & .07 & .04 & .08 & .03 \\
\hline Guess & .02 & .03 & .04 & .04 & .03 & .03 & .07 & .08 & .03 & .02 & .05 & .03 \\
\hline
\end{tabular}


signal detection measure, $A^{\prime}$, which, following Donaldson's (1996) lead, has been widely used in previous studies. Neither of these analyses altered the main conclusions to be drawn.

For example, the mean $A^{\prime}$ estimates of memory strength for remember responses and for know responses from all four experiments are summarized in Table 5 . There continues to be some controversy about the use of such measures for remember and know responses and about whether a unidimensional signal detection model can account for the results of studies in which the rememberknow paradigm is used (see, e.g., Dunn, 2004; Gardiner, Ramponi, \& Richardson-Klavehn, 2002; Macmillan, Rotello, \& Verde, 2005; Rotello, Macmillan, \& Reeder, 2004). Macmillan et al., for example, argued that separate $A^{\prime}$ estimates for know responses do not provide good measures of memory accuracy and are not relevant to testing a unidimensional model. Accordingly, we present such measures here merely as a measurement device that yields corrected recognition scores, given each state of awareness, and to preserve continuity with the many previous studies in which they have been reported.

It is apparent that these estimates reveal a pattern of results across experiments very similar to that revealed by the raw reports of the states of awareness. In Experiment 1 , there were significant effects of response deadline $\left[F(1,46)=4.42, M S_{\mathrm{e}}=0.01\right]$ and size congruence $\left[F(1,46)=26.62, M S_{\mathrm{e}}=0.01\right]$ in estimates of remembering, and there was also a significant interaction between those effects $\left[F(1,46)=4.05, M S_{\mathrm{e}}=0.01\right]$; the effect of response deadline in knowing was marginal $[F(1,46)=$ 3.27, $\left.M S_{\mathrm{e}}=0.02, p<.08\right]$. In Experiment 2, there were significant effects of response deadline $[F(1,46)=22.82$, $\left.M S_{\mathrm{e}}=0.02\right]$ and voice congruence $[F(1,46)=130.85$, $\left.M S_{\mathrm{e}}=0.02\right]$ in estimates of remembering but only of response deadline in estimates of knowing $[F(1,46)=$ 25.60, $\left.M S_{\mathrm{e}}=0.01\right]$. In Experiment 3, the effects of response deadline $\left[F(1,46)=6.70, M S_{\mathrm{e}}=0.01\right]$ and size congruence $\left[F(1,46)=37.01, M S_{\mathrm{e}}=0.01\right]$ were significant in estimates of knowing, but not of remembering. And in Experiment 4, the effects of response deadline $\left[F(1,46)=5.26, M S_{\mathrm{e}}=0.01\right]$ and voice congruence $\left[F(1,46)=37.42, M S_{\mathrm{e}}=0.01\right]$ were significant in esti-

Table 5

Mean $A^{\prime}$ Estimates of Memory Strength for

Remembering and for Knowing in Experiments 1-4

\begin{tabular}{|c|c|c|c|c|c|}
\hline & \multirow{2}{*}{$\begin{array}{c}\text { State of } \\
\text { Awareness }\end{array}$} & \multicolumn{2}{|c|}{ Congruent } & \multicolumn{2}{|c|}{ Incongruent } \\
\hline & & Fast & Slow & Fast & Slow \\
\hline \multirow[t]{2}{*}{ Experiment 1} & Remembering & .80 & .85 & .79 & .81 \\
\hline & Knowing & .71 & .75 & .71 & .77 \\
\hline \multirow{2}{*}{ Experiment 2} & Remembering & .79 & .84 & .72 & .77 \\
\hline & Knowing & .68 & .71 & .67 & .74 \\
\hline \multirow{2}{*}{ Experiment 3} & Remembering & .78 & .80 & .78 & .79 \\
\hline & Knowing & .74 & .77 & .69 & .74 \\
\hline \multirow{2}{*}{ Experiment 4} & Remembering & .71 & .77 & .72 & .76 \\
\hline & Knowing & .75 & .79 & .68 & .73 \\
\hline
\end{tabular}

Note-Rows with mean $A^{\prime}$ estimates in bold indicate significant effects of both study-test congruence and response deadline. mates of knowing, but only the effect of response deadline was significant in estimates of remembering $[F(1,46)=$ 9.25, $\left.M S_{\mathrm{e}}=0.01\right]$.

Thus, regardless of the appropriateness or otherwise of these estimates for particular theoretical purposes, they provided strong converging evidence to support the conclusions drawn if the reported states of awareness are considered the primary data, rather than secondary measures that may be derived from the primary data.

Other secondary measures that have commonly been derived from the reported states of awareness include estimates of recollection and familiarity processes in dualprocess models (Yonelinas, 2002; Yonelinas \& Jacoby, 1995). Yonelinas did not include such process estimates from Gardiner et al.'s (1999) article in his database. He argued that they were inappropriate in this paradigm because it is the recognition judgments that are speeded, not the reports of the states of awareness. This argument is mistaken. The timing of the reports is immaterial, since in standard yes/no recognition tests, they are always retrospective and refer to the state of awareness in preceding recognition judgments. Estimates of recollection and of familiarity from Experiments 1-4 are summarized in Table 6. These estimates were calculated to take false alarm rates into account, following the formulae used by Yonelinas (2002; see, also, Yonelinas \& Jacoby, 1995). The probability of a remember response is taken as an index of recollection, and the probability of a know response divided by one minus the estimate of recollection is taken as an index of familiarity. In each case, separate estimates are derived for the false alarm rates and subtracted from those derived from the hit rates.

Estimates of recollection differ little from the raw proportions of correct remember responses, because the corresponding false alarm rates tend to be so low. Statistically, conclusions to be drawn from these estimates did not differ from those drawn from previous analyses, and so we will not describe them further. Estimates of familiarity often show a pattern different from that found in the raw proportions of correct know responses, especially when effects in remembering are accompanied by the absence of any effects in knowing. Thus, the pattern of results summarized in Table 6 differs from that observed in the previous analyses, in that familiarity estimates appear to indicate effects of both study-test congruence and response deadline, regardless of whether or not both effects were observed in know responses. For familiarity estimates in Experiment 1, the effects of both response deadline $\left[F(1,46)=8.87, M S_{\mathrm{e}}=0.06\right]$ and size congruence $\left[F(1,46)=5.51, M S_{\mathrm{e}}=0.06\right]$ were significant, and there was no interaction. For familiarity estimates in Experiment 2, the effect of response deadline was significant $\left[F(1,46)=36.58, M S_{\mathrm{e}}=0.02\right]$, the effect of size congruence was very marginally significant $[F(1,46)=$ $\left.3.72, M S_{\mathrm{e}}=0.02 . p<.06\right]$, and there was no interaction. For familiarity estimates in Experiment 3, the effects of both response deadline $\left[F(1,46)=27.11, M S_{\mathrm{e}}=0.02\right]$ and size congruence $\left[F(1,46)=47.00, M S_{\mathrm{e}}=0.02\right]$ were significant, and there was no interaction. And for familiar- 


\begin{tabular}{|c|c|c|c|c|c|c|c|c|c|}
\hline & $\begin{array}{c}\text { Mean Process E } \\
\text { Recollection }\end{array}$ & Ima & bl & 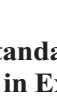 & 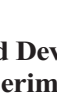 & 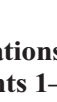 & & & \\
\hline & & & Con & uent & & & Incol & ruent & \\
\hline & Process & & & & & & & & \\
\hline & Estimated & $M$ & $S D$ & $M$ & $\overline{S D}$ & $M$ & $S D$ & $M$ & $S D$ \\
\hline Experiment 1 & Recollection & .33 & .11 & .46 & .15 & .27 & .13 & .35 & .16 \\
\hline & Familiarity & .32 & .20 & .48 & .22 & .27 & .15 & .42 & .20 \\
\hline Experiment 2 & Recollection & .26 & .11 & .41 & .09 & .13 & .10 & .24 & .10 \\
\hline & Familiarity & .18 & .10 & .37 & .17 & .13 & .09 & .32 & .16 \\
\hline Experiment 3 & Recollection & .25 & .12 & .29 & .10 & .26 & .15 & .28 & .13 \\
\hline & Familiarity & .27 & .10 & .41 & .10 & .17 & .10 & .31 & .11 \\
\hline Experiment 4 & Recollection & .09 & .05 & .17 & .08 & .10 & .07 & .20 & .12 \\
\hline & Familiarity & .29 & .08 & .46 & .18 & .16 & .12 & .28 & .13 \\
\hline
\end{tabular}

Note-Rows with mean estimates in bold indicate significant effects of both study-test congruence and response deadline in familiarity.

ity estimates in Experiment 1, the effects of both response deadline $\left[F(1,46)=21.39, M S_{\mathrm{e}}=0.01\right]$ and size congruence $\left[F(1,46)=42.98, M S_{\mathrm{e}}=0.01\right]$ were significant, and there was no interaction. Thus, the statistical conclusion from these analyses is that familiarity was, in general, influenced by effects of both study-test congruence and response deadline in a way similar to that for recollection.

The general effects of study-test congruence on familiarity replicate the results obtained by Yonelinas and Jacoby (1995) in the estimates of familiarity that they derived for the effects of size congruence, using the independence remember-know model, as well as in other estimates that they derived using Jacoby's (1991) process dissociation procedure. So whether or not one has reservations about the appropriateness of deriving such estimates from remember and know responses in a response deadline procedure, there is a remarkable consistency in the pattern of results across the different procedures and studies. Previous studies are also consistent with the present results in showing a general tendency for familiarity estimates to be higher with slow than with fast recognition judgments, however those estimates are derived (see, e.g., Gardiner et al., 1999; Konstantinou \& Gardiner, 2005; Yonelinas, 2002). In all cases, the effects of response deadline in remembering and in recollection tend to be mirrored by similar effects in knowing and in familiarity. The implication is that the two processes, as well as the two states of awareness, are, to some extent, similarly dependent on the conscious resources available at retrieval.

\section{DISCUSSION}

The main trends in the results of these four experiments seem clear. With full attention at encoding, the perceptual effects of size and voice congruence occurred in remembering, as they normally do (see, also, Gardiner et al., 2001; Karayianni \& Gardiner, 2003; Rajaram, 1996). With divided attention at encoding, these perceptual effects occurred, instead, in knowing (see, also, Gardiner et al., 2001; Karayianni \& Gardiner, 2003). These perceptual effects were generally unaffected by the speed with which recognition judgments had to be made, and they were as- sociated with the same state of awareness regardless of whether those judgments were fast or slow (see, also, Gardiner et al., 2005; Gardiner et al., 1999; Konstantinou \& Gardiner, 2005). Also, knowing, as well as remembering, tended to increase with slow, as compared with fast, recognition judgments - in some cases, to pretty much the same extent as did remembering. Corrected recognition scores yielded similar conclusions with respect to these experimental outcomes, as did estimates of recollection and familiarity processes derived from the independence remember-know model (Yonelinas \& Jacoby, 1995). Familiarity estimates yielded the additional conclusion that the perceptual effects of congruence occurred in that process even when they did not occur in knowing, but only in remembering (see, also, Yonelinas \& Jacoby, 1995).

The experiments were motivated by the need for further evidence concerning the extent to which effects in remembering and knowing, and these two states of awareness themselves, depend on the conscious resources available at encoding and at retrieval. They were predicated on the widely held assumptions that remembering depends on consciously controlled, strategic, and effortful processing, whereas knowing is more automatic, nonstrategic, and reflexive. These rather general assumptions have been held both by theorists who attribute remembering and knowing to episodic and semantic memory systems, respectively (see, e.g., Levine et al., 1999; Tulving, 1983), and by those who attribute remembering and knowing to qualitatively distinct processes (see, e.g., Jacoby, 1991). Our findings qualify these assumptions, particularly with respect to the impact of the conscious resources available at retrieval, rather than at encoding.

At encoding, our findings provide additional evidence that with reduced conscious resources, effects that normally occur in remembering occur, instead, in knowing. That outcome provides direct support for Tulving's (1995) SPI model in indicating that effects may be encoded into semantic memory under conditions that appear to preclude their being additionally encoded into episodic memory. Since the conditions that appear to preclude this are those most likely to make it difficult to achieve more distinctive encoding, the occurrence, then, of effects in 
knowing, instead of in remembering, also provides good support for Rajaram's (1996) distinctiveness/fluency account. Presumably, perceptual congruence then gives rise to greater processing fluency at test, rather than to the reinstatement of more distinctive processing. That these perceptual effects can occur either in remembering or in knowing also provides further evidence against the earlier suggestion that only conceptual processes influence remembering and only perceptual processes influence knowing (Rajaram, 1993). Process estimates from the independence remember-know model (Yonelinas \& Jacoby, 1995) confirmed that these perceptual effects were not evident in the recollection process with reduced conscious resources at encoding. However, the effects were evident in the familiarity process regardless of conscious resources at encoding, a conclusion that is consistent with the assumption that the familiarity process is more automatic than is recollection.

Thus, so far as encoding is concerned, the results seem to provide good support for these several theoretical accounts, as well as for their shared assumptions about the dependence of the two states of awareness, remembering and knowing, upon the conscious resources available. But it is important to note that the generality of the dependence on encoding conditions of this transfer of effects from remembering to knowing, as Gardiner et al. (2001) described it, remains largely unknown. The present experiments confirm that this transfer of effects holds for perceptual study-test congruence, but there is evidence that at least some other effects do not show a similar transfer. Reducing the conscious resources available at encoding has been found to eliminate or even reverse the word frequency effect, for example (Balota, Burgess, Cortese, \& Adams, 2002; Hirshman, Fisher, Henthorn, Arndt, \& Passannante, 2002; Joordens \& Hockley, 2000), which is another effect that normally occurs in remembering (Gardiner \& Java, 1990). Gregg, Gardiner, Karayianni, and Konstantinou (2006) found that with a divided attention task very similar to that used in the present experiments, although the overall low-frequency advantage was eliminated, that effect persisted in remembering but was offset by a high-frequency advantage in know responses. Thus, there is no evidence that reducing the conscious resources available at encoding leads to a transfer of the lowfrequency advantage from remembering to knowing. There is also some evidence that under other, less demanding conditions of impoverished encoding than those used in the present experiments, the transfer of perceptual effects may be partial, rather than complete, with effects in both remembering and in knowing, as well as effects either only in remembering or only in knowing (see Karayianni \& Gardiner, 2003). The generality of effects being observed in knowing, instead of in remembering, or observed in knowing as well as in remembering may present something of a challenge for the SPI, dual-process, and distinctiveness/fluency models, since they would need to be additionally refined to account for such results.

The word frequency effect has also been found to be eliminated with speeded recognition tests (Joordens \&
Hockley, 2000), an outcome that provides further evidence for its dependence on more consciously controlled processing, but now at retrieval, rather than at encoding. In contrast, the perceptual effects of study-test congruence, like levels-of-processing effects (Gardiner et al., 1999; Konstantinou \& Gardiner, 2005), were found to be very little affected by fast, as compared with slow, recognition decisions (see, too, Gardiner et al., 2005). Not only were these effects little influenced at the behavioral level by differences in the time allowed for recognition judgments and, hence, differences in the conscious resources available at retrieval, but also there was no indication of any effects in knowing even with fast judgments. The effects remained, either in remembering or in knowing, regardless of recognition speed. Those results are contrary to the hypothesis that even with full attention at encoding, the effects might be observed in knowing under retrieval conditions that could be assumed to reduce controlled processing and, hence, recollection (see, e.g., Boldini et al., 2004; Toth, 1996).

Taken altogether, the results indicate that the occurrence of perceptual effects of study-test congruence in either remembering or knowing is more dependent on the conscious resources available at encoding than on those available at retrieval, an outcome that is consistent with Tulving's (1993) coordination hypothesis. Of course, we cannot discount the possibility that the pattern of results we observed might change were it possible to attain even faster recognition decisions than those made at the short response deadline, and in that respect, the boundary conditions of our results remain uncertain. But in that regard, it is also important to note that the response deadlines we chose were similar to those used in many previous studies that have provided evidence to support dual-process models (e.g., Jacoby et al., 1998; Toth, 1996).

The occurrence of similar perceptual effects in remembering under more automatic conditions of retrieval also calls into question the extent to which remembering itself reflects more controlled, effortful retrieval processes. It suggests that to an appreciable extent, remembering may have been triggered automatically at retrieval. By the same token, the increase in knowing with slow, as compared with fast, recognition judgments, which was quite substantial in some conditions, suggests that knowing may benefit from slower, more controlled processing at retrieval (see, also, Gardiner et al., 1999; Konstantinou \& Gardiner, 2005). Thus, the correspondence generally assumed between the two states of awareness, remembering and knowing, and between the amounts of conscious resources they entail seems significantly weaker at retrieval than at encoding. The evidence argues against simply identifying one dichotomy, remembering versus knowing, with another dichotomy, consciously controlled and strategic processing versus automatic and nonstrategic processing. The situation is more complicated than that, and it requires a looser, more orthogonal view of the memorial states of awareness and the conscious resources they require, particularly at retrieval. Similar arguments have been made on the basis of other evidence, including comparisons between per- 
formance in intentional and incidental tests of word stem completion and estimates derived from inclusion and exclusion tests using the process dissociation procedure (see, e.g., Richardson-Klavehn \& Gardiner, 1996; RichardsonKlavehn, Gardiner, \& Ramponi, 2002).

There is also other evidence that recognition associated with remembering may be faster than recognition associated with knowing. For example, Dewhurst and Conway (1994) found that response latencies for recognition judgments associated with remembering were, on average, shorter than those associated with knowing, and similar findings have been reported by Dewhurst, Holmes, Brandt, and Dean (2006) and by Gallo, Donaldson, and Dolan (2002). Evidence that remembering, to some extent, reflects more automatic retrieval and that knowing, to some extent, reflects more consciously controlled retrieval raises problems for dual-process theories that equate knowing with automatic processing and remembering with controlled processing (for more discussion, see RichardsonKlavehn et al., 1996; Richardson-Klavehn et al., 2002). Knowing may sometimes involve more controlled processing because it sometimes follows a more protracted evaluation of mental experiences that argue against remembering (some experiences of remembering might be misplaced), of other mental experiences that suggest a recent but unremembered encounter, or of both.

Estimates of recollection and familiarity processes derived from the independence remember-know model were ancillary to our main purposes but supported conclusions drawn from analyses of simple response proportions and from corrected recognition scores, with the exception of indicating effects of perceptual congruence in the familiarity process even when no such effects were evident in knowing. Similar perceptual effects in the familiarity process when no such effects were evident in knowing had also been found by Yonelinas and Jacoby (1995) in normal, unspeeded recognition tests (see, too, Yonelinas, 2002), and their results, as well as ours, have been generally congruent with those that we have found in speeded recognition tests (see, also, Gardiner et al., 2005). That in itself suggests that there are no methodological reasons why reports of remembering and knowing, and any process estimates derived from them, should not be made in conjunction with speeded recognition decisions. The participants were quite clear that reports of remembering and knowing referred to the mental experiences associated with the recognition judgments, as is always the case, regardless of the speed of those judgments. It is, therefore, the timing of those judgments, not of the subsequent reports, that is critical. Even so, the participants had to make these reports immediately after their yes responses, and they were not allowed to hesitate in doing so.

In one experiment, Gardiner et al. (2005) compared speeded picture recognition involving yes/no judgments followed by reports of remembering (the standard twostage response procedure) with speeded reports of remembering (a one-stage response procedure). It can be hypothesized that because recollection is a slower process, there might be more reports of remembering with the two-stage procedure than with the one-stage procedure if participants have experiences of remembering after making a yes judgment that they then misattribute to that judgment. The results were quite the reverse. Proportions of both remember responses and estimates of recollection were much greater with the one-stage procedure. Signal detection measures, used to separate criteria effects from effects of memory, revealed that these differences were entirely attributable to the adoption of a much more lenient response criterion with the one-stage procedure. Estimates of memory strength did not differ. Similar effects on response criteria, in comparing two-stage with one-stage test procedures, have been found by Eldridge, Sarfatti, and Knowlton (2002) and by Hicks and Marsh (1999), although with unspeeded, not speeded, recognition tests. The implication is that the two test procedures affect decision processes but not memory processes.

Decision processes are, of course, central to other theoretical accounts of remembering and knowing based on signal detection models, and although our experiments were not designed to test such models, we will conclude with a few brief remarks about them. There continues to be controversy about whether a unidimensional signal detection model that essentially ascribes remembering and knowing to a continuum of trace strength or confidence can account for all the results of remember-know experiments. For example, Dunn (2004; see, also, Wixted \& Stretch, 2004) has shown how a unidimensional model can fit the results of a database of some 400 different experimental conditions, reviving a claim originally made in a similar meta-analysis by Donaldson (1996; see, also, Hirshman \& Lanning, 1999; Hirshman \& Master, 1997; Inoue \& Bellezza, 1998), whereas others have, for various reasons, argued against a unidimensional model (see, e.g., Conway, Dewhurst, Pearson, \& Sapute, 2001; Gardiner et al., 2002; Macmillan et al., 2005; see, also, Rotello et al., 2004).

Here, we wish to add only one further comment. Although the occurrence of size and voice congruence effects in know responses in the absence of effects in remember responses provides some support for all three of the theoretical approaches with which we have been chiefly concerned, it raises problems for a unidimensional signal detection model. ${ }^{1}$ Because both levels of congruence involved the same participants and only one set of lures, the decision criteria must be common to both levels. Hence, congruence can only affect memory strength. But if the proportions of remember responses (or stronger items, in this model) are the same for congruent and incongruent items, as they were under divided attention conditions, memory strength must be the same for congruent and incongruent items. The proportions of know responses (or weaker items in this model) should, therefore, also be the same for congruent and incongruent items. Thus, at least as we understand it, the problem for this model is to explain how size and voice congruence appeared, paradoxically, to influence trace strength for know responses and, at the same time, not influence trace strength for remember responses. 


\section{REFERENCES}

Anderson, N. D. (2001). The attentional demands and attentional control of encoding and retrieval. In M. Naveh-Benjamin, M. Moscovitch, \& H. L. Roediger III (Eds.), Perspectives on human memory and cognitive aging: Essays in honour of Fergus Craik (pp. 208-225). New York: Psychology Press.

Balota, D. A., Burgess, G. C., Cortese, M. J., \& Adams, D. R. (2002). The word-frequency mirror effect in young, old, and early-stage Alzheimer's disease: Evidence for two processes in episodic recognition performance. Journal of Memory \& Language, 46, 199-226.

Boldini, A., Russo, R., \& Avons, S. E. (2004). One process is not enough! A speed-accuracy tradeoff study of recognition memory. Psychonomic Bulletin \& Review, 11, 353-361.

Conway, M. A., Dewhurst, S. A., Pearson, N., \& Sapute, A. (2001). The self and recollection reconsidered: How a "failure to replicate" failed and why trace strength accounts of recollection are untenable. Applied Cognitive Psychology, 15, 673-686.

Curran, T. (2000). Brain potentials of recollection and familiarity. Memory \& Cognition, 28, 923-938.

Curran, T., \& Cleary, A. M. (2003). Using ERPs to dissociate recollection from familiarity in picture recognition. Cognitive Brain Research, 15, 191-205.

Dewhurst, S. A., \& Conway, M. A. (1994). Pictures, images, and recollective experience. Journal of Experimental Psychology: Learning, Memory, \& Cognition, 20, 1088-1098.

Dewhurst, S. A., Holmes, S. J., Brandt, K. R., \& Dean, G. M. (2006). Measuring the speed of the conscious components of recognition memory: Remembering is faster than knowing. Consciousness \& Cognition, 15, 147-162.

DonALDSON, W. (1996). The role of decision processes in remembering and knowing. Memory \& Cognition, 24, 523-533.

DunN, J. C. (2004). Remember-know: A matter of confidence. Psychological Review, 111, 524-542.

Eldridge, L. L., Sarfatti, S., \& Knowlton, B. J. (2002). The effect of testing procedure on remember-know judgments. Psychonomic Bulletin \& Review, 9, 139-145.

Gallo, D. A., Donaldson, D. I., \& Dolan, P. O. (2002, November). Waiting for recollection, fast recollection, or illusory recollection: What do response latencies tell us? Paper presented at the 43rd Annual Meeting of the Psychonomic Society, Kansas City.

Gardiner, J. M. (1988). Functional aspects of recollective experience. Memory \& Cognition, 16, 309-313.

Gardiner, J. M., \& Conway, M. A. (1999). Levels of awareness and varieties of experience. In B. H. Challis \& B. M. Velichkovsky (Eds.), Stratification in cognition and consciousness (pp. 237-254). Amsterdam: Benjamins.

Gardiner, J. M., Gregg, V. H., Mashru, R., \& Thaman, M. (2001). Impact of encoding depth on awareness of perceptual effects in recognition memory. Memory \& Cognition, 29, 433-440.

GARDINER, J. M., \& JAVA, R. I. (1990). Recollective experience in word and nonword recognition. Memory \& Cognition, 18, 23-30.

Gardiner, J. M., Konstantinou, I., Karayianni, I., \& GregG, V. H. (2005). Memory awareness following speeded compared with unspeeded picture recognition. Experimental Psychology, 52, 140-149.

GARDINER, J. M., \& PARKIN, A. J. (1990). Attention and recollective experience in recognition memory. Memory \& Cognition, 18, 579-583.

Gardiner, J. M., Ramponi, C., \& Richardson-Klavehn, A. (1999). Response deadline and subjective awareness in recognition memory. Consciousness \& Cognition, 8, 484-496.

Gardiner, J. M., RAMPONI, C., \& Richardson-KLAVEhn, A. (2002). Recognition memory and decision processes: A meta-analysis of remember, know, and guess responses. Memory, 10, 83-98.

Gardiner, J. M., \& Richardson-Klavehn, A. (2000). Remembering and knowing. In E. Tulving \& F. I. M. Craik (Eds.), Handbook of memory (pp. 229-244). Oxford: Oxford University Press.

GregG, V. H., Gardiner, J. M., Karayianni, I., \& Konstantinou, I. (2006). Recognition memory and awareness: A high-frequency advantage in the accuracy of knowing. Memory, 14, 265-275.

HiCKS, J. L., \& MARSH, R. L. (1999). Remember-know judgments can depend on how memory is tested. Psychonomic Bulletin \& Review, 6, 117-122.
Higham, P. A., \& Vokey, J. R. (2004). Illusory recollection and dualprocess models of recognition memory. Quarterly Journal of Experimental Psychology, 57A, 714-744.

Hirshman, E., Fisher, J., Henthorn, T., Arndt, J., \& Passannante, A. (2002). Midazolam amnesia and dual-process models of the wordfrequency mirror effect. Journal of Memory \& Language, 47, 499516.

HiRShMAN, E., \& LANNING, K. (1999). Is there a special association between self judgments and conscious recollection? Applied Cognitive Psychology, 13, 29-42.

Hirshman, E., \& Master, S. (1997). Modeling the conscious correlates of recognition memory: Reflections on the remember-know paradigm. Memory \& Cognition, 25, 345-351.

Inoue, C., \& Bellezza, F. S. (1998). The detection model of recognition using know and remember judgments. Memory \& Cognition, 26, 299-308.

JACOBY, L. L. (1991). A process dissociation framework: Separating automatic from intentional uses of memory. Journal of Memory \& Language, 30, 513-541.

JaCoBy, L. L., Jones, T. C., \& Dolan, P. O. (1998). Two effects of repetition: Support for a dual-process model of know judgments and exclusion errors. Psychonomic Bulletin \& Review, 5, 705-709.

Jacoby, L. L., Yonelinas, A. P., \& Jennings, J. M. (1997). The relation between conscious and unconscious (automatic) influences: A declaration of independence. In J. D. Cohen \& J. W. Schooler (Eds.), Scientific approaches to consciousness (pp. 13-47). Mahwah, NJ: Erlbaum.

Joordens, S., \& HockLEY, W. E. (2000). Recollection and familiarity through the looking glass: When old does not mirror new. Journal of Experimental Psychology: Learning, Memory, \& Cognition, 26, 1534-1555.

KARAYIANNI, I., \& GARDINER, J. M. (2003). Transferring voice effects in recognition memory from remembering to knowing. Memory \& Cognition, 31, 1052-1059.

Konstantinou, I., \& Gardiner, J. M. (2005). Conscious control and memory awareness when recognising famous faces. Memory, 13, 449457.

KuČERA, H., \& FrANCIS, W. N. (1967). Computational analysis of presentday American English. Providence, RI: Brown University Press.

Levine, B., Freedman, M., Dawson, D., Black, S., \& Stuss, D. T. (1999). Ventral frontal contribution to self-regulation: Convergence of episodic memory and inhibition. Neurocase, 5, 263-275.

Macmillan, N. A., Rotello, C. M., \& Verde, M. F. (2005). On the importance of models in interpreting remember-know experiments: Comments on Gardiner et al.'s (2002) meta-analysis. Memory, 13, 83-98.

MandLeR, G. A. (1980). Recognizing: The judgment of previous occurrence. Psychological Review, 87, 252-271.

Mangels, J. A., Picton, T. W., \& Craik, F. I. M. (2001). Attention and successful episodic encoding: An event-related potential study. Cognitive Brain Research, 11, 77-95.

Parkin, A. J., Gardiner, J. M., \& Rosser, R. (1995). Functional aspects of face recognition. Consciousness \& Cognition, 4, 387-398.

RAJARAM, S. (1993). Remembering and knowing: Two means of access to the personal past. Memory \& Cognition, 21, 89-102.

Rajaram, S. (1996). Perceptual effects on remembering: Recollective processes in picture recognition memory. Journal of Experimental Psychology: Learning, Memory, \& Cognition, 22, 365-377.

RAJARAM, S. (1999). Assessing the nature of retrieval experience: Advances and challenges. In B. H. Challis \& B. M. Velichkovsky (Eds.), Stratification in cognition and consciousness (pp. 255-275). Amsterdam: Benjamins.

Rajaram, S., \& Geraci, L. (2000). Conceptual fluency selectively influences knowing. Journal of Experimental Psychology: Learning, Memory, \& Cognition, 26, 1070-1074.

RichaRdSON-KLAVEHN, A., \& GARDINER, J. M. (1996). Cross-modality priming in stem completion reflects conscious memory, but not voluntary memory. Psychonomic Bulletin \& Review, 3, 238-244.

Richardson-Klavehn, A., Gardiner, J. M., \& JaVa, R. I. (1996). Memory: Task dissociations, process dissociations, and dissociations of consciousness. In G. D. M. Underwood (Ed.), Implicit cognition (pp. 85-155). Oxford: Oxford University Press. 
Richardson-Klavehn, A., Gardiner, J. M., \& Ramponi, C. (2002). Level of processing and the process-dissociation procedure: Elusiveness of null effects on estimates of automatic retrieval. Memory, 10, 349-364.

Rotello, C. M., Macmillan, N. A., \& Reeder, J. A. (2004). Sumdifference theory of remembering and knowing: A two-dimensional detection theory model. Psychological Review, 111, 588-616.

Rugg, M. D., Schloerscheidt, A. M., \& Mark, R. E. (1998). An electrophysiological comparison of two indices of recollection. Journal of Memory \& Language, 39, 47-69.

SNODGRASS, J. G., \& VANDERWART, M. (1980). A standardized list of 260 pictures: Norms for name agreement, image agreement, familiarity, and visual complexity. Journal of Experimental Psychology: Human Learning \& Memory, 6, 174-215.

Tотн, J. P. (1996). Conceptual automaticity in recognition memory: Levels-of-processing effects on familiarity. Canadian Journal of Experimental Psychology, 50, 123-138.

Tulving, E. (1983). Elements of episodic memory. Oxford: Oxford University Press, Clarendon Press.

Tulving, E. (1985). Memory and consciousness. Canadian Psychology, 26, 1-12.

Tulving, E. (1993). Varieties of consciousness and levels of awareness in memory. In A. Baddeley \& L. Weiskrantz (Eds.), Attention: Selection, awareness, and control. A tribute to Donald Broadbent (pp. 283299). Oxford: Oxford University Press, Clarendon Press.

Tulving, E. (1995). Organization of memory: Quo vadis? In M. S. Gazzaniga (Ed.), The cognitive neurosciences (pp. 839-847). Cambridge, MA: MIT Press.
Tulving, E. (2002). Episodic memory: From mind to brain. Annual Review of Psychology, 53, 1-25.

Tulving, E. (2005). Episodic memory and autonoesis: Uniquely human? In H. S. Terrace \& J. Metcalfe (Eds.), The missing link in cognition: Origins of self-reflective consciousness (pp. 3-56). New York: Oxford University Press.

Van Petten, C., Coulson, S., Rubin, S., Plante, E., \& Parks, M. (1999). Time course of word identification and semantic integration in spoken language. Journal of Experimental Psychology: Learning, Memory, \& Cognition, 25, 394-417.

WiXted, J. T., \& STRETCH, V. (2004). In defense of the signal detection interpretation of remember/know judgments. Psychonomic Bulletin \& Review, 11, 616-641.

Yonelinas, A. P. (2002). The nature of recollection and familiarity: A review of 30 years of research. Journal of Memory \& Language, 46, 441-517.

Yonelinas, A. P., \& JACOBY, L. L. (1995). The relation between remembering and knowing as bases for recognition: Effects of size congruency. Journal of Memory \& Language, 34, 622-643.

\section{NOTE}

1. We are grateful to John Dunn for kindly drawing this point to our attention in his review of an earlier version of this article; our comment here is based on his remarks.

(Manuscript received November 10, 2004; revision accepted for publication February 24, 2005.) 